\title{
Peningkatan pemahaman ibu hamil tentang ASI eksklusif di kelurahan Gedung Johor Medan
}

\author{
Surya Anita ${ }^{*}$, Dewi Rismauli Bancin ${ }^{1}$, Friska Sitorus ${ }^{1}$ \\ 1Program Studi Profesi Bidan, Fakultas Farmasi dan Ilmu Kesehatan, Universitas Sari Mutiara Indonesia, Medan, Indonesia
}

DOI: $\underline{\text { https://doi.org/10.29303/indra.v2i2.124 }}$

\section{Article Info}

Received : 02-08-2021

Revised : 28-09-2021

Accepted: 29-09-2021

\begin{abstract}
Understanding of pregnant women about exclusive breastfeeding as evidenced by Exclusive breastfeeding is breastfeeding from birth until the child is 6 months old. During this period children are not expected to get additional fluids, such as formula milk, lemon juice, tea water, honey, and plain water. In exclusive breastfeeding, children are also not given additional food such as bananas, biscuits, rice porridge, teams, and so on. Exclusive breastfeeding for up to 6 months can meet the needs of children, and requires additional food at the age of over 6 months (Maryunani, 2012). The role of midwives in promoting exclusive breastfeeding can be started from the time the mother is pregnant. When pregnant women check their pregnancies, pregnant women will get information about the benefits of breastfeeding and how to successfully breastfeed when their babies are born (Atik, 2016). This activity was carried out in juni 2021, the Covid-19 pandemic then the participant who follows there were 20 mother pregnant and this activity went smoothly.
\end{abstract}

Keywords: Exclusive, pregnant woman, breastfeeding

Citation: Anita, S., Bancin, D.R., \& Sitorus, F. (2021). Peningkatan Pemahaman Ibu Hamil Tentang ASI Eksklusif Di Kelurahan Gedung Johor Medan. INDRA: Jurnal Pengabdian kepada Masyarakat, 2(2), 41-44. doi: https://doi.org/10.29303/indra.v2i2.124

\section{Pendahuluan}

Air susu ibu (ASI) merupakan sumber gizi dengan komposisi seimbang untuk kebutuhan pertumbuhan dan perkembangan bayi. ASI adalah makanan lengkap untuk bayi, dan kandungan gizi dalam ASI berupa kalori, vitamin, dan mineral adalah yang terbaik untuk bayi karena memiliki proporsi yang sesuai. ASI harus diberikan secara eksklusif, yaitu selama 6 bulan tanpa makanan tambahan lain seperti susu formula, jeruk, madu, air teh, air mineral dan makanan padat seperti pisang, pepaya, bubur susu, biskuit, bubur nasi, dan tim sejak lahir hingga bayi umur 6 bulan (Fikawati dkk, 2015).

Cakupan Kunjungan Neonatal Pertama atau KN1 merupakan indikator yang menggambarkan upaya kesehatan yang dilakukan untuk mengurangi risiko kematian pada periode neonatal yaitu 6-48 jam setelah lahir yang meliputi antara lain kunjungan menggunakan pendekatan. Manajemen Terpadu Balita Muda (MTBM) termasuk konseling perawatan bayi baru lahir, ASI eksklusif, pemberian vitamin K1 injeksi dan Hepatitis B0 injeksi bila belum diberikan. Capaian KN1 Indonesia pada tahun 2016 sebesar 91,14\% lebih tinggi dari tahun 2015 yaitu sebesar 83,67\%. Namun beberapa provinsi mendapatkan cakupan lebih dari $100 \%$ dikarenakan data sasaran BPS lebih rendah dibandingkan dengan data sasaran riil yang didapatkan. Sehingga data yang diperoleh berbeda dengan angka kejadian KN1 di Indonesia, dan menyebabkan konseling mengenai ASI eksklusif pun tidak maksimal, sehingga cakupan pemberian ASI eksklusif di Indonesia pun masih belum mencapai target. Menurut WHO (2016), pemberian ASI eksklusif di dunia masih berkisar 39\%. Dan jika dibandingkan dengan target $\mathrm{WHO}$ yaitu sebesar $50 \%$, angka tersebut masih jauh dari target. Sementara capaian ASI eksklusif 
di Indonesia yang diharapkan yaitu sebesar $80 \%$. Dari hasil Pemantauan Status Gizi (PSG) tahun 2016, persentase bayi $0-5$ bulan yang tidak mendapat ASI eksklusif sebesar $54,0 \%$, sedangkan bayi yang telah mendapatkan ASI eksklusif sampai usia enam bulan adalah sebesar 29,5\% (Kementerian Kesehatan RI, 2017).

Salah satu upaya pemerintah dalam meningkatkan pemberian ASI eksklusif, demi mewujudkan derajat kesehatan masyarakat yang lebih baik pada tahun 2016-2017 adalah Gerakan Masyarakat Hidup Sehat (GERMAS) (Kementerian Kesehatan RI, 2017).

Pengetahuan ibu yang kurang mengetahui dan memahami tata laksana laktasi yang benar juga akan mempengaruhi pemberian ASI eksklusif pada bayi. Misalnya, pentingnya memberikan ASI, bagaimana ASI keluar, bagaimana posisi menyusui dan perlekatan yang baik sehingga ASI dapat keluar dengan optimal (Astutik, 2013). Faktor ekskternal ibu adalah segala sesuatu yang berasal di luar diri ibu, seperti dukungan suami dan tenaga kesehatan. Faktor-faktor tersebut sangat mempengaruhi pemberian ASI eksklusif pada bayi. Sehingga jika salah satu faktor tersebut tidak teraplikasikan dengan baik dan benar pada ibu menyusui, maka hal tersebut akan mempengaruhi rendahnya pemberian ASI eksklusif 5 pada bayi (Maulida dkk, 2015).

Penelitian Andayani dkk (2017) menyebutkan bahwa, terdapat hubungan antara persepsi produksi ASI yang kurang pada ibu dengan pemberian ASI eksklusif. Ini berarti bahwa ibu yang memiliki persepsi produksi ASI yang kurang, cenderung memiliki cakupan ASI eksklusif yang lebih rendah. Sebaliknya, ibu yang tidak memiliki persepsi produksi ASI yang kurang, cenderung untuk memiliki cakupan ASI eksklusif yang lebih tinggi, dan berdasarkan penelitian Lumenta (2017), dari 64 ibu didapati ibu yang bekerja dan tidak memberikan ASI eksklusif sebanyak $37 \mathrm{ibu}$ (57,8\%) dan ibu yang bekerja dan memberikan ASI eksklusif yaitu sebanyak $27 \mathrm{ibu}(42,2 \%)$. Sedangkan hubungan dukungan tenaga kesehatan dengan pemberian ASI eksklusif yaitu diperoleh data bahwa jumlah ibu yang menyatakan dukungan tenaga kesehatan baik yaitu 18 ibu (17.1\%), yang memberikan ASI Eksklusif 18 ibu (17.1\%) dan yang tidak memberikan 0 ibu $(0 \%)$, sedangkan jumlah ibu yang menyatakan dukungan tenaga kesehatan kurang baik sebanyak $87 \mathrm{ibu}(82.9 \%)$, yang memberikan ASI Eksklusif $72 \mathrm{ibu}(68.6 \%)$ dan yang tidak memberikan ASI Eksklusif $15 \mathrm{ibu}(14.3 \%)$.

Berdasarkan data Puskesmas Medan Johor tahun 2021, dari 472 orang ibu hanya $35 \%$ (167 orang) yang memberikan ASI eksklusif kepada bayinya. Sedangkan ibu yang tidak memberikan ASI eksklusif pada bayi sebesar $65 \%$ (305 orang). Namun, berdasarkan studi awal yang dilakukan di desa Kelurahan Gedung Johor tahun 2021, diperoleh data dari 15 orang ibu hamil hanya $50 \%$ yang paham tentang ASI Ekslusif dan akan memberikan ASI secara ekslusif nanti kepada bayinya, selebihnya tidak paham tentang ASI Ekslusif.

\section{Metode}

ASI Eksklusif adalah bayi hanya diberi asi saja selama 6 bulan, tanpa tambahan cairan lain seperti susu formula, jeruk, madu, air, teh dan air putih, serta tanpa tambahan makanan padat seperti pisang, bubur susu, biscuit, bubur nasi, dan nasi tim. Setelah 6 bulan baru mulai diberikan makanan pendamping ASI (MPASI) (Maryunani, 2012). Pemberian ASI eksklusif atau menyusui eksklusif adalah memberikan ASI hanya pada bayi dan tidak memberi bayi makanan atau minuman lain, termasuk air putih, kecuali obat-obatan dan vitamin atau mineral tetes; ASI perah juga diperbolehkan, yang dilakukan sampai bayi berumur 6 bulan (Wiji, 2013).

Lokasi kegitan ini dilaksanakan di Kelurahan Gedung Johor tepatnya di kantor lurah, peserta yang mengikuti kegiatan ini adalah ibu-ibu hamil trimester III dikarenakan masa pandemi peserta hanya dibatasi 20 orang dengan protokol kesehatan yang ketat. Tahapan pelaksanaan kegiatan ini sebagai berikut:

1. Survey awal untuk melihat jumlah ibu hamil di Kelurahan Gedung Johor untuk memeriksakan kehamilan dengan tetap mengikuti protokol kesehatan.

2. Pembuatan materi dengan menggunakan leaflet dan alat peraga lainnya tentang ASI Ekslusif.

3. Sebelum pelaksnaaan kegiatan dihimbau kepada ibu hamil yang datang untuk tetap mematuhi protokol kesehatan seperti menggunakan masker, mencuci tangan di wastafel yang sudah disediakan kemudian duduk di tempat yang telah disediakan.

4. Kegiatan penyuluhan ini dilaksnakan dalam 2 tahap untuk menghindari kerumunan, setiap tahap diikuti oleh 10 orang ibu hamil dengan hari yang berbeda sehingga total semua ibu hamil yang mengikuti kegiatan sejumlah 20 orang.

Kegiatan dimulai pukul 10.00 - 11.30 .

5. Materi yang disampaikan meliputi : Pengertian ASI Ekslusif; Tujuan pemberian ASI Ekslusif; Keuntungan pemberian ASI Ekslusif, Gizi untuk ibu hamil dan manyusui, Cara-cara agar ASI ibu banyak.

6. Pada setiap sesi pelaksanaan penyuluhan dibagikan kuis pre penyuluhan dan post penyuluhan sebagai bahan untuk Evaluasi keberhasilan pelaksanaan penyuluhan

7. Penyusunan laporan kegiatan pengabdian masyarakat 
Pengolahan data yang dilaksanakan adalah dengan melihat perbandingan nilai pre dan pos tes dari setiap peserta.

\section{Hasil dan Pembahasan Hasil}

Tabel 1. Rekapitulasi Nilai Pre Tes Peserta Kegiatan

\begin{tabular}{cccc}
\hline No & Range Nilai & Jumlah & Persentse \\
\hline 1 & $0-60$ & 12 & 60 \\
2 & $61-100$ & 8 & 40 \\
& Total & 20 & 100 \\
\hline
\end{tabular}

Dari tabel 1 diatas dapat dilihat bahwa berdasarkan nilai pre tes responden mayoritas mendapatkan nilai pada range 0 - 60 yaitu $60 \%$.

Tabel 2. Rekapitulasi Nilai Pos Tes Peserta Kegiatan

\begin{tabular}{cccc}
\hline No & Range Nilai & Jumlah & Persentse \\
\hline 1 & $0-60$ & 5 & 25 \\
2 & $61-100$ & 15 & 75 \\
& Total & 20 & 100 \\
\hline
\end{tabular}

Dari tabel 2 diatas dapat dilihat bahwa berdasarkan nilai pos tes responden mayoritas mendapatkan nilai pada range $61-100$ yaitu $75 \%$.

\section{Pembahasan}

Pengabdian masyarakat ini bertujuan untuk meningkatkan pemahaman ibu hamil trimester III tentang ASI Ekslusif sehingga pada saat ibu-ibu hamil ini melahirkan maka dapat memberikan ASI Ekslusif. Pengabdian masyarakat ini melibatakan mahasiswa pendidikan profesi bidan dan dosen yang dikoordinir oleh Surya Anita, Dewi Rismauli Bancin dan Friska Sitorus. Dari hasil pengabdian masyarakat tentang peningkatan pemahaman ibu hamil tentang ASI Ekslusif dilihat dari hasil pre dan pos tes adanya peningkatan pemahaman ibu hamil tentang ASI Ekslusif.

Pemberi penyuluhan harus menguasai ilmu komunikasi dan menguasai pemahaman yang lengkap dan jelas tentang pesan yang akan disampaikan serta pemakaian media dan alat peraga yang sesuai dan tepat agar tujuan penyuluhan dapat di capai secara optimal dan efektif. Tujuan penyuluhan ini adalah :

1. Tercapainya perubahan prilaku individu, keluarga dan masyarakat dalam membina dan memelihara prilaku sehat dan lingkungan sehat, serta berperan aktif dalam upaya mewujudkan derajat kesehatan yang optimal.

2. Terbentuknya prilaku sehat pada individu, keluarga, kelompok dan masyarakat sesuai dengan konsep hidup sehat.

3. Mengubah prilaku seseorang dan/atau masyarakat dalam bidang kesehatan (Maryam, 2015).

Berdasarkan kajian ilmiah, menyusui dapat meningkatkan kecerdasan anak, karena menyusui memberikan pelekatan erat dan rasa nyaman yang berpengaruh terhadap perkembangan intelegensia dan emosi anak. Faktor yang mempengaruhi kecerdasan anak yaitu faktor genetik yang merupakan faktor kecerdasan yang diturunkaan dari orangtua dan faktor lingkungan yang berupa asuh, asah, dan asih. Asuh yaitu kebutuhan pertumbuhan fisik dan otak, dapat dipenuhi dengan cara pemberian asupan makanan pada bayi. Masa lompatan pertumbuhan otak adalah 06 bulan, bahkan dua tahun. Bayi yang mengalami kekurangan zat gizi berat pada masa ini akan mengakibatkan pengurangan sel otak $15 \%-20 \%$. Asah yaitu kebutuhan perkembangan intelektual dan sosialisasi, membutuhkan stimulasi, rangsangan, dan pendidikan yang diberikan kepada bayi. Ibu yang sering menyusui bayinya membuat bayi terbiasa berhubungan dengan orang lain dan dengan demikian perkembangan sosialisasinya akan baik dan mudah berinteraksi dengan lingkungan. Asih merupakan kebutuhan perkembangan emosional dan spiritual. Anak yang mendapatkan ASI akan mendapatkan kasih sayang dan rasa aman. Seorang yang merasa disayangi akan mampu menyayangi lingkungannya dan akan mampu bekembang menjadi manusia dengan budi pekerti dan nurani yang baik. Seorang bayi yang merasa aman dan dilindungi, akan berkembang menjadi orang dewasa yang mandiri dengan emosi yang stabil (Haryono dan Setitaningsih, 2014).

Hasil penelitian ini sesuai dengan penelitian yang dilakukan Lestari dan Zuraidah (2013), pemberian ASI eksklusif dipengaruhi oleh beberapa faktor, antara lain usia dan pengetahuan. Ibu yang berumur 30 tahun ke atas yang memberikan ASI eksklusif sebesar 45,5\%, sedangkan ibu yang berusia di bawah 30 tahun hanya $18,3 \%$ yang memberikan ASI eksklusif. Pemberian ASI dipengaruhi oleh tingkat pengetahuan, ibu dengan pengetahuan baik yang memberikan ASI eksklusif sebesar $50,0 \%(p=0,02)$, sedangkan ibu yang memiliki pengetahuan kurang baik yang memberikan ASI eksklusif sebesar $47,8 \%$ pengetahuan ibu yang kurang baik juga dikarenakan informasi dari petugas kesehatan yang hanya $40 \%$ memberikan promosi kesehatan tentang ASI Eksklusif.

\section{Simpulan}

Berdasarkan hasil pengabdian masyarakat tentang ASI Ekslusif di kelurahan Gedung Johor Medan maka dapat diambil kesimpulan bahwa 20 orang ibu hamil sudah mendapatkan penyuluhan pendidikan kesehatan tentang ASI Ekslusif.

\section{Ucapan Terima Kasih}

1. Terima kasih kepada Lurah Gedung Johor yang telah memberikan kesempatan untuk melaksanakan pengabdian masyarakat ini 
2. Terima kasih kepda Rektor USM-Indonesia yang mendukung setiap kegiatan Tridharma perguruan tinggi

3. Terima kasih kepada seluruh peserta ibu-ibu hamil yang sudah mengikuti kegiatan ini dengan tekun hingga selesai

\section{Daftar Pustaka}

Andayani, Dwi. Emilia, Ova. Ismail, Djauhar. (2017). Peran Kelas Ibu Hamil Terhadap Pmeberian ASI Eksklusif di Gunung Kidul. Berita Kedokteran Masyarakat, 3(7), 317-324.

Astuti, I. (2013). Determinan Pemberian ASI Eksklusif Pada Ibu Menyusui . Jurnal Health Quality, 4(1), $1-76$.

Fikawati, S,. A. Syafiq,. K, Karima. (2015). Gizi Ibu dan Bayi. Jakarta: PT Rajagrafindo Persada.

Haryono, R., dan S. Setianingsih. (2014). Manfaat Asi Eksklusif untuk Buah Hati Anda. Yogyakarta: Gosyen Publishing.

Kementrian Kesehatan RI. (2017). Situasi dan Analisis ASI Ekslusif. Jakarta: Pusdatin (Pusat Data dan Informasi) Kemenkes RI.

Lestari, D., R. Zuraida., dan TA. Larasati. (2013). Hubungan Tingkat Pengetahuan Ibu tentang Air Susu Ibu dan Pekerjaan Ibu dengan Pemberian ASI Eksklusif di Kelurahan Fajar Bulan. Medical Journal of Lampung University, 2(4), 88-99.

Lumenta, P.G., Adam, H, dan Engkeng, S. (2017). Hubungan Antara Pengetahuan Ibu dan Faktor Sosial Ekonomi dengan Pemberian Asi Eksklusif di Wilayah Kerja Puskesmas Wolaang Kecamatan Langowan Timur. Journal Health, 6(3), $1-9$.

Maulida, H., Afifah, E., dan Sari, D.P. (2015). Tingkat Ekonomi dan Motivasi Ibu dalam Pemberian ASI Eksklusif pada Bayi Usia 0-6 Bulan di Bidan Praktek Swasta (BPS) Ummi Latifah Argomulyo, Sedayu Yogyakarta. Journal Ners and Midwifery Indonesia, 3(2), 116-122.

Maryam, S. (2015). Promosi Kesehatan. Jakarta : Buku Kedokteran EGC.
Maryunani, A. (2012). Inisiasi Menyusu Dini, Asi Eksklusif dan Manajemen Laktasi. Jakarta: CV Trans Info Media.

Wiji, R.N. (2013). ASI dan Pedoman Ibu Menyusui. Yogyakarta: Nuha Medika. 